\title{
SOMETIMES SOME THINGS DON'T (REALLY) EXIST: PRAGMATIC MEINONGISM AND THE REFERENTIAL SUB-PROBLEM OF NEGATIVE EXISTENTIALS
}

\author{
LENNY CLAPP \\ Northern Illinois University \\ Department of Philosophy \\ lclapp@niu.edu
}

SUMMARY: To solve the referential sub-problem of negative existentials one must explain why we interpret uses of, e.g., 'Sherlock Holmes doesn't exist' as saying something coherent and intuitively true, even though the speaker purports to refer to something. Pragmatic Meinongism solves this problem by allowing 'does not exist' to be pragmatically modulated to express an inclusive sense under which it can be satisfied by something. I establish three points in defense of pragmatic Meinongism: (i) it is superior to Russell-inspired solutions; (ii) it is supported by independent evidence of pragmatic modulation; and (iii) it requires no dubious ontological commitments.

KEY WORDS: pragmatic modulation, truth conditional pragmatics, ontological commitment, fictional realism, real existence

RESUMEN: Para resolver el sub-problema referencial de los existenciales negativos, uno debe explicar por que interpretamos usos de, por ejemplo, "Sherlock Holmes no existe" como diciendo algo coherente e intuitivamente verdadero, aunque el hablante intenta referirse a algo. El meinongismo pragmático resuelve este problema al permitir que "no existe" sea pragmáticamente modulado para expresar un sentido inclusivo según el cual puede ser satisfecho por algo. En este trabajo establezco tres puntos en defensa del meinongismo pragmático: (1) es superior a las soluciones inspiradas por Russell, (ii) es apoyado por evidencia independiente de modulación pragmática, y (iii) no requiere compromisos ontológicos dudosos.

PALABRAS CLAVE: modulación pragmática, pragmática veritativo-condicional, compromiso ontológico, realismo ficcional, existencia real

We have all been prone to say, in our common-sense usage of exist, that Pegasus does not exist, meaning simply that there is no such entity at all. (Quine 1948, p. 3)

Yes, Virginia, there is a Sherlock Holmes. (Salmon 1998, p. 293)

\section{The Problems of Negative Existentials and Pragmatic Meinongism}

The problem of negative existentials, or at least the problem that will concern me here, is the problem of explaining why sentences of 
the form $\ulcorner N$ does not exist $\urcorner$ (where $N$ is a presupposition-triggering definite noun-phrase) can be used to say something intuitively true. ${ }^{1}$ Why do competent interpreters understand occurrences of, e.g., 'Sherlock Holmes does not exist' as saying something true (and perhaps even informative)? If the speaker is interpreted as using 'Sherlock Holmes' to refer to something, then how can she be correct to assert of it that it does not exist? But if the speaker is not interpreted as using 'Sherlock Homes' to refer to something, then how can she be interpreted as saying anything at all, much less something true?

There is, however, no reason to assume that one explanation applies to all intuitively true uses of such negative existential sentences, and significant headway is gained by distinguishing between two categories of such uses, thereby dividing the problem into two sub-problems. The two categories of use are distinguished by what competent speakers would say in response to this test question: "In uttering $\ulcorner N$ does not exist $\urcorner$, is the speaker purporting to use $N$ to refer to something and to assert of it that it does not exist?" Uses for which the intuitively correct response is "no" give rise to the nonreferential sub-problem. The challenge posed by this sub-problem is to explain why we understand a speaker of ${ }^{\ulcorner} N$ does not exist ${ }^{\urcorner}$ as saying something true, given that we think that in using $N$ the speaker is not even purporting to refer to something. Here the challenge is not as much to explain why we think what the speaker said is true, as it is to explain why we interpret the speaker as having said anything truth-evaluable at all. If the speaker is not even purporting to assert of something that it does not exist, how can we think that she has said anything at all, much less something true? In contrast, uses for which the intuitively correct response to the test question is "yes" give rise to the referential sub-problem. The complementary challenge raised by this second sub-problem is to explain how we interpret a speaker of $\ulcorner N$ does not exist $\urcorner$ as having said something true, given that we think that in using $N$ the speaker at least purports to refer to something. If we competent interpreters think that in using $N$ the speaker presents herself as having referred to something, then how can we think she is even saying something coherent, much less true, when she asserts of $i t$ that it does not exist?

\footnotetext{
${ }^{1}$ Negative existential sentences whose subject-terms are bare plurals or generic terms raise a different set of issues. See Moltmann (2013), (2020) for a linguistic analysis of these alternative forms.
} 
A crucial first step for solving the non-referential sub-problem is to recognize that it arises only when negative existential sentences are used to perform the speech act of correcting a target assertion that is judged by the speaker to be infelicitous due to reference failure. ${ }^{2}$ Suppose that Urbain and Albert are discussing the perturbations of Mercury's orbit, and the following exchange occurs:

Urbain: Vulcan exerts a powerful gravitational force on Mercury. Albert: No, Vulcan does not (even) exist.

In using 'Vulcan does not exist' to correct Urbain's previous assertion, Albert is not purporting to use 'Vulcan' to refer to something and then asserting of it that it does not exist; rather Albert is -in a somewhat deviant and playful way- rejecting Urbain's previous assertion and justifying that rejection on the grounds that Urbain failed to refer to anything with his initial use of 'Vulcan'. Recognizing that the non-referential problem arises when negative existentials are used to perform such corrections does not itself constitute a solution to the non-referential problem; an adequate solution requires explaining why we understand Albert's correction as saying something true, even though we think that in using (not mentioning!) 'Vulcan' Albert has not even purported to refer to anything. Providing such an explanation requires getting clear about how the processes of presupposition accommodation interact with the non-monotonic illocutionary force of correction. I present such an explanation elsewhere, ${ }^{3}$ so here my

${ }^{2}$ This claim is too strong, as there seem to be instances of the non-referential sub-problem where the speaker does not target a specific assertion. I am not aware, however, of any instances of the non-referential sub-problem that do not involve correction.

${ }^{3}$ In Clapp (forthcoming) I present the requisite explanation within a version of Segmented Discourse Representation Theory. In broad outline, what is going in exchange ( 1 ) is that the existential presupposition triggered by Urbain's initial use of 'Vulcan' in (la) must be accommodated by we interpreters, but, given Albert's subsequent correction in (lb), our only way of coherently accommodating this existential information is to include it within the information that is nullified by Albert's correction - nullification is an aspect of the illocutionary force of correction, and nullified information is truth-conditionally inert. The presupposition triggered by Albert's subsequent use of 'Vulcan' is then resolved by being bound to the nullified existential information. Albert's somewhat deviant correction is felicitous because the presupposition triggered by his use of 'Vulcan' is bound to information previously introduced (via accommodation), but at the same time his correction does not require for its truth that there be such a thing as Vulcan, as this previously introduced existential information is nullified by the illocutionary force of his own speech act. The upshot is that Albert is interpreted as denying the existence of 
focus will be on the other sub-problem, viz. the referential problem of negative existentials.

Suppose a speaker is prompted, "Tell me about Sherlock Holmes", and in response she utters, "OK", followed by,

(1) Sherlock Holmes doesn't (really) exist; he's (just) a fictional character.

In uttering (1) the speaker is not saying, as Quine (1948, p. 3) would put it, that "there is no such entity at all" as Sherlock Holmes; rather in uttering (1) the speaker is at least purporting to refer to something with her use of 'Sherlock Holmes' and to assert of it that it does not exist. ${ }^{4}$ Note that the felicity of the speaker's anaphoric use of 'he' in the follow-up clause compels us to adopt this referential interpretation. We do not hear this use of 'he' as infelicitous as a result of lacking a proper antecedent; rather we interpret the speaker as using 'he' to refer to the very thing that she purported to refer to using 'Sherlock Holmes' and then asserting of it that it is a fictional character. ${ }^{5}$ Felicitous interpretation of the anaphoric pronoun thus requires that we take the speaker as having at least purported to refer to something with her use of 'Sherlock Holmes' and having asserted of it that it does not exist. But this raises the referential subproblem: How can we interpret the speaker of (1) as saying something coherent, much less true? How even could there be something that satisfies 'does not exist'?

The key to solving the referential sub-problem is to recognize that 'does not exist' is like nearly all other natural language predicates in that it is subject to pragmatic modulation. That is, though as a matter of its conventional linguistic meaning the inflected verb-phrase 'does not exist' is context-sensitive only in the way that every other tense-inflected verb-phrase is context-sensitive, its satisfaction conditions nonetheless vary across uses, depending upon the exigencies of

—as it were - the very thing Urbain has purported to refer to, yet Albert is not interpreted as purporting to refer to anything.

${ }^{4}$ Some philosophers, e.g. Kripke (2013), would say that a speaker who utters (1) does not really say something true. But what requires explanation is that we understand the speaker as at least seeming to say something true.

${ }^{5}$ Some may want to classify the anaphora displayed in (1) as a case of Geach's (1967) "intentional identity." I have no objection to this classification, beyond pointing out that it does not solve the referential sub-problem. 
the discourse situations in which such uses occur. ${ }^{6}$ Though evidence suggests that the default interpretation of 'exists' aligns with Quine's dictum that "to [exist] is to be the value of a variable" (Quine 1948, p. 34), and thus 'does not exist' is typically interpreted in such a way that nothing can satisfy it, ${ }^{7}$ evidence also suggests that pragmatic constraints sometimes prompt the satisfaction conditions of a use of "does not exist' to be "broadened" to allow for the possibility that some things do satisfy 'does not exist'.

The solution I am proposing to the referential sub-problem thus resembles the views of Meinong (1960): I agree with Meinong that in uttering (1) the speaker is at least purporting to refer to something and to assert of $i t$ that it does not exist. But there are significant differences between my proposal and Meinong's. ${ }^{8}$ First, I maintain that for some uses of intuitively true negative existentials —uses that give rise to the non-referential problem - the speaker does not even purport to refer to something. Second, I do not think that the satisfaction conditions of every use of 'does not exist' allows for satisfaction by some things; uses of 'does not exist' that give rise to the non-referential sub-problem are understood in such a way that nothing can satisfy this predicate. And third, I do not claim that in purporting to refer to something a speaker thereby succeeds in referring to something; in my view understanding a use of (l) as saying something intuitively true requires that we interpret the speaker as purporting to assert of something that it does not exist, but my view does not require ontological commitment to non-existent entities.

Given these similarities and differences with Meinong's approach, I call my proposed solution to the referential sub-problem pragmatic

${ }^{6}$ In the terms of Recanati (2010), the contextual variability manifested by 'does not exist' cannot be explained as a form of saturation; it can be accounted for only by a primary pragmatic process of modulation. Sainsbury suggests that some fictional realists "explore treating "exists' as ambiguous, or context-sensitive" (2009, p. 109). This suggestion is on the right track, but the contextual variability of "does not exist' is not plausibly explained by either semantic context-sensitivity or lexical ambiguity.

${ }^{7}$ As Kripke (2013, p. 145) observes, a speaker who utters 'Napoleon might not have existed' is not understood as saying that Napoleon might have differed in some way from how he actually is; rather she is understood as saying that it might have been that nothing is Napoleon.

${ }^{8}$ More recent proposals in the spirit of Meinong's view are presented by Parsons (1980), Priest (2005) and Zalta (1988). Pragmatic Meinongism also differs from these Meinong-inspired views, as none of them take into account the pragmatic modulation of 'does not exist'. 
Meinongism. My purpose here is to defend this solution by demonstrating its superiority over a competing, Russell-inspired, proposal for solving the sub-problem. My defense proceeds as follows: In section 2, I explain why the referential sub-problem seems to be especially pressing for fictional realism, and I review Salmon's (1998) Russell-inspired proposal for solving this problem. In section 3, I show that Salmon's solution is inadequate for two reasons: first, it does not even apply to instances of the referential sub-problem outside the domain of metafictional discourse; and second, even within this limited domain it fails to provide an adequate solution. In section 4, I develop pragmatic Meinongism and respond to the worry that its appeal to the pragmatic modulation of 'does not exist' is ad hoc. Finally, in section 5, I conclude by explaining why — despite what one might initially think - pragmatic Meinongism does not imply ontological commitment to fictional characters, numbers, possible men in the doorway, or any other suspicious entities; even those who share Russell's parsimonious "feeling for reality" (Russell 1919, p. 169) can endorse pragmatic Meinongism.

\section{Fictional Realism and the Referential Sub-Problem}

Fictional realists such as van Inwagen ((1977) (2003), Kripke (2013), Salmon (1998), and Thomasson (1999) maintain the ontological view that there are such things as fictional characters, and moreover they maintain that in metafictional discourse - discourse about fictionnames for fictional characters are used to refer to such entities. So, fictional realists maintain that a speaker who utters, e.g.,

(2) Sherlock Holmes is widely admired by Arthur Conan Doyle's readers.

not only purports to use 'Sherlock Holmes' to refer to something, but moreover successfully uses 'Sherlock Holmes' to refer to something. Fictional realists do not maintain that this referent is a person, but rather a certain sort of abstract object. ${ }^{9}$ Given that abstract objects can be widely admired, fictional realism is able to provide a straightforward explanation of the intuitive truth of metafictional claims such

\footnotetext{
${ }^{9}$ Fictional realists differ as to the precise nature of such abstract entities. Most prominent fictional realists maintain that fictional entities are created in the process of creating and appreciating works of fiction, though there is some disagreement about precisely how they are created. Another kind of fictional realism would maintain that fictional objects are eternal objects; van Inwagen (2003) at least considers this sort of Platonic view. These differences will not concern me here.
} 
as (2). What motivates the ontological profligacy of fictional realists such as van Inwagen et al. is precisely the desire to keep purported reference and intuitive truth in alignment with successful reference and literal truth.

But this ontological profligacy seems to come at a cost. For fictional realism also seems to entail that a speaker who sincerely utters,

(0) Sherlock Holmes does not exist.

succeeds in saying something that is literally false. If a speaker who utters (2) says something true because she successfully uses 'Sherlock Holmes' to refer to something that is widely admired, then a speaker who utters $(0)$ - especially a speaker who utters $(0)$ in the process of uttering (1) ${ }^{10}$ - must also be using 'Sherlock Holmes' to refer to something; but to refer to something and then assert of it that it does not exist would, it seems, be to say something incoherent. This prediction of incoherence, however, conflicts with the datum that we competent interpreters typically understand a speaker who utters $(0)$ — even a speaker who utters (0) in the process of uttering (1) - as saying something not only coherent, but moreover intuitively true. The referential sub-problem thus seems to be particularly pressing for fictional realists.

The problem has not gone unnoticed by fictional realists. I will focus here on Salmon's (1998, pp. 303-304) Russell-inspired proposed solution, both because Salmon's presentation is more detailed than other similar proposals and because it is paradigmatic of a common Russell-inspired strategy for solving the problem. ${ }^{11}$ In the following lengthy citation, Salmon presents his explanation as to why - despite what seems to be predicted by fictional realism - we understand a speaker who utters (0) as saying something true:

We sometimes use ordinary names, especially names of famous people, in various descriptive ways, as when it is said that so-and-so is

${ }^{10}$ Salmon initially presents the problem he is attempting to solve in terms of (0), but he suggests that this problem is "better yet" (1998, p. 303) presented in terms of (1); I assume Salmon's reasoning here, which I endorse, is that the presence of the anaphoric pronoun indicates that the speaker at least purports to be referring to something with her antecedent use of 'Sherlock Holmes'.

${ }^{11}$ Van Inwagen (2003), Thomasson (1999), and von Solodkoff (2014) all deploy Russell-inspired solutions, though these other Russell-inspired proposals are notably silent, and perhaps a bit confused, about the semantic or pragmatic mechanisms that could result in a speaker who utters, e.g., (0) saying something equivalent to a negated existential quantification. 
a Napoleon, or a Nixon, another Hitler, no Jack Kennedy, or even (to segue to the fictional realm) a Romeo, an Uncle Tom, quixotic, Pickwickian, etc. I submit that, especially in singular existential statements, we sometimes use the name of a fictional character in a similar way. We may use 'Sherlock Holmes', for example, to mean something like: Holmes more or less as he is actually depicted in the stories, or Holmes replete with these attributes [the principally salient ones ascribed to Holmes in the stories], or best, the person who is both Holmes and Holmesesque. In uttering (0), one would then mean that the Holmes of fiction, Holmes as depicted, does not exist in reality, that there is in reality no such person - no such person, no person who is both Holmes and sufficiently like that (as depicted in fiction).

Since this interpretation requires a reinterpretation of the name, it might be more correct to say that the speaker expresses this proposition than to say that (0) itself does. This is not a use of 'Holmes' as a thoroughly nonreferring name, but as a kind of description that invokes the name of the fictional character. In short, the name is used a là Russell as a disguised improper definite description. [...] Let us say that someone is a Holmesesque-Holmes if he is Holmes and sufficiently like he is depicted to be, in the sense that he has relevantly many of the noteworthy attributes that Holmes has according to the stories. Perhaps the most significant of these is the attribute of being a person (or at least person-like) and not an abstract artifact. Following Russell, to say that the Holmesesque-Holmes does not exist is to say that nothing is uniquely both Holmes and Holmesesque. ${ }^{12}$ (1998, p. 304)

Salmon's proposal, in short, is to apply a version of Russell's (1905) descriptivism to explain why we interpret a speaker who utters (0) as saying something true. We can understand the solution as proceeding in two steps. The first step — which occurs in the first paragraph in the above citation - is to claim that the proposition the speaker of (0) expresses is adequately characterized by a sentence in which the name 'Sherlock Holmes' is replaced by an "improper definition description":

(0)' The Holmesesque-Holmes does not exist.

What the first step effectively does is to posit a "non-standard use" (1998, 304) of fictional names that has the effect of transforming the referential sub-problem posed by a use of (0) into an instance of the

\footnotetext{
${ }^{12}$ The brackets appear in the original text. But where I have 'Holmes' Salmon's original text has 'Holmes,'. Salmon's distinction between 'Holmes' and 'Holmes,' is irrelevant to my purposes.
} 
non-referential problem. Why? Because the subject term of $(0)^{\prime}$ necessarily lacks a referent; nothing could satisfy the contrived restricting noun 'Holmesesque-Holmes', since Holmes is an abstract object, and no abstract object could be Holmesesque - no abstract object could be a human being who smokes a pipe, etc. Moreover, Salmon's motivation for selecting this necessarily "improper definite description" is that the speaker knows it is improper - the whole point of Salmon's Russell-inspired proposal is for the speaker to replace 'Sherlock Holmes' — which, according to Salmon, successfully referswith a proxy subject term that not only fails to refer, but moreover is known by the speaker - and presumably by her audience as wellto fail to refer.

The second step consists of applying Russell's (1905) proposed solution to the general problem of negative existentials to the nonreferential negative existential claim depicted by $(0)^{\prime}$; the core of this proposal is thus to apply Russell's analysis of definite descriptions to the "improper" definite description occurring in $(0)^{\prime}$. There are three noteworthy components of this analysis (each of which is dubious): first, the definite article is analyzed as an indefinite, nonpresupposition-triggering, existential quantifier; second, the negation in the verb-phrase 'does not exist' is analyzed as having (only) widescope over this existential quantifier; and third, the (now redundant) predicate 'does exist' is surreptitiously excised. The result is Salmon's final Russell-inspired analysis:

$$
(0)^{\prime \prime} \sim(\exists ! \mathrm{x})[\text { Holmesesque }(\mathrm{x}) \&(\mathrm{x}=\text { Holmes })]
$$

As Salmon notes, the interpretation represented by $(0)^{\prime \prime}$ can be more colloquially expressed as "nothing is uniquely both Holmes and Holmesesque". And since nothing could be both Holmesesque and also be identical to Holmes, the interpretation depicted by $(0)^{\prime \prime}$ is true.

\section{Two Objections Against Salmon's Russell-inspired Proposal}

My first objection against Salmon's proposal is that it fails to generalize. This sort of objection has been previously raised against Russellinspired fictional realists. Perhaps most notably, Everett (2007) forcefully argues that Thomasson's (1998) Russell-inspired proposal fails to generalize because there is no guarantee that a relevant work of fiction will provide sufficiently rich descriptive information that might 
be "disguised" by the name of a fictional character. ${ }^{13}$ My objection, however, is not merely that Salmon's Russell-inspired proposal fails to generalize to all intuitively true uses of negative existentials whose subject terms are alleged by fictional realists to refer to existing fictional characters, but rather that it fails to generalize to all instances of the referential sub-problem. Now, to be sure, that Salmon's Russell-inspired solution fails to generalize in this way constitutes an objection against Salmon's proposal only if it ought to generalize in this way. To establish that Salmon's solution ought to apply to all instances of the referential sub-problem, it suffices to demonstrate that the problem posed by negative existentials such as (0) and (1) arises independently of the ontological stance of fictional realism. That is, the problem Salmon's Russell-inspired proposal is supposed to solve arises independently of the question of the ontological status of fictional characters, and thus we should require of an adequate solution to that problem that it solve all its instances, not just those instances that happen to arise within the domain of metafictional discourse.

Suppose we agree that fictional realism is false; sorry Virginia, there is no Santa Claus. This ontological stipulation does nothing to obviate the fundamental problem raised by (1). Even if we grant that the speaker of (1) does not successfully refer to something with her use of 'Sherlock Holmes', still — as indicated by the anaphoric use of 'he' in the follow-up - we must concede that she purports to refer to something. And that the speaker purports to refer to something with her use of 'Sherlock Holmes' is enough to generate the problem that Salmon's Russell-inspired solution is attempting solve. That is, given that we $d o$ interpret the speaker of (1) as purporting to refer to something and to assert of it that it does not exist, why do we not interpret the speaker of (1) as making an assertion (or purporting to make an assertion) that incoherently implies that there is something that does not exist? Indeed, far from interpreting a use of (1) as being incoherent, we competent interpreters typically understand a speaker of (1) as saying something true. But how can this be? How can a speaker even coherently purport to refer to something and assert of it that it does not exist? That is the fundamental problem raised

${ }^{13}$ Everett (2007) has us consider a speaker whose only belief about a certain fictional character named 'Yugo' is that Yugo is a fictional character. For such a speaker, being Yugo-esque is equivalent to being a fictional character. Applying the Russell-inspired analysis in such a case will produce the unwanted result that an utterance of 'Yugo does not exist' is false, since in this case something is both Yugo and Yugo-esque - viz. Yugo. 
by occurrences of (1), and it arises independently of the ontological status of fictional characters.

Consider these negative existentials:

(3) That man in the doorway doesn't (really) exist; he's (just) a possible object.

(4) Nineteen doesn't (really) exist; it's (just) a mathematical construction.

These sentences are analogous in obvious ways with (1), and they give rise to the same problem - viz. the referential sub-problem. Consider (4). Regardless of our views concerning the ontological status of numbers, we competent interpreters understand a speaker of (4) as purporting to use 'Nineteen' to refer to something and to assert of $i t$ that it does not exist, but - though we may disagree with the speaker's ontological claim - we do not understand the speaker of (4) as saying (or purporting to say) something incoherent. Similar remarks apply to (3), and countless other negative existentials. But Salmon's Russell-inspired proposal does not even apply to the instances of the referential sub-problem manifested by uses of (3) and (4). Even if Salmon is correct that every fictional name $F$ allows for a "nonstandard use" (1998, p. 304) whereby $F$ functions as a "disguised" improper definite description of the form $\ulcorner$ the F-esque $F\urcorner$, this is no help with regard to the problem as it arises outside the domain of metafictional discourse, e.g. with regard to the instances of the sub-problem manifested by uses of (3) and (4). Moreover, the prospects of somehow extending Salmon's Russell-inspired proposal so that it could apply to all instances of the referential sub-problem are bleak: though it is at least plausible that there is a nonstandard communicative practice whereby speakers use 'Sherlock Holmes' as a sort of obviously "improper" disguised definite description, it is not plausible that there is an analogous practice of using, e.g., 'Nineteen' as a disguised obviously "improper" definite description.

My first objection against Salmon's Russell-inspired proposal is that it is not an adequate solution to the problem it is attempting to solve, because it does not even apply outside the domain of metafictional discourse. The fundamental problem raised by negative existentials such as (1) is the referential sub-problem, and this problem arises outside of metafictional discourse. That Salmon's proposed solution does not even apply to all instances of the problem it is attempting to solve suggests that even within this domain Salmon's 
proposed solution must be missing the mark, and my second objection demonstrates that this is the case: even within the domain of metafictional discourse Salmon's Russell-inspired proposal is hopelessly inadequate.

My second objection concerns the transformation that occurs in the first step of Salmon's analysis, the transformation from an instance of the referential sub-problem, to an instance of the non-referential subproblem. This transformation would be legitimate if the use of (0) were interpreted as falling into the first category of use - the category characterized by a response of "no" to the test-question - but the relevant uses of (0) are not so interpreted: the referential sub-problem arises specifically when we interpret the speaker as at least purporting to use 'Sherlock Holmes' to refer to something and assert of it that it does not exist. The first step of Salmon's Russell-inspired analysis in effect denies that a use of $(0)$ even gives rise to the referential sub-problem, since under Salmon's proposal the speaker of (0) does not even purport to use 'Sherlock Holmes' to refer to something, but instead uses it in a non-standard way as an "improper" "disguiseddescription" (1998, p. 304). My second objection against Salmon's proposed solution is that speakers of typical uses of sentences such as $(0)-e . g .(0)$ as it appears in a use of $(1)-d o$ at least purport to use 'Sherlock Holmes' to refer to something, and thus such uses do give rise to the referential sub-problem. ${ }^{14}$ A way of bringing out the problem is to consider the anaphoric occurrence of 'he' in the follow-up clause of (1). I noted above that the presence of this anaphoric pronoun, whose antecedent is the previous use of 'Sherlock Holmes', indicates that the speaker is at least purporting to use 'Sherlock Holmes' to refer. The problem is that under Salmon's Russell-inspired analysis, this referential use of 'Sherlock Holmes' is analyzed away, and with it goes a suitable antecedent for the subsequent anaphoric 'he'.

Let us walk through the problem. According to the first step of Salmon's Russell-inspired analysis, what a speaker says in uttering (1) is depicted by

$(1)^{\prime}$ The Holmesesque-Holmes does not exist, and he is a fictional entity.

${ }^{14}$ The first step is also puzzling within the dialectical setting of Salmon's (1998) paper. Salmon's overall strategy is to argue that the non-referential problem - which Salmon describes as "a Headache" (p. 308) - "on closer inspection, frequently vanishes" (p. 286). But, Salmon's closer inspection of (0) leads to the appearance of the non-referential problem where it does not appear prior to the inspection. 
One might suppose that the definite description 'The HolmesesqueHolmes' serves as a suitable antecedent for the subsequent anaphoric pronoun 'he'. But in supposing this one would be assuming that the speaker is at least purporting to use this definite description to refer to something, and this assumption is precisely what is denied in the second step of Salmon's analysis. According to Salmon's analysis, the "improper" definite description is not a suitable antecedent, since on a Russellian analysis it is not a referential term at all. That is, according to the second step of Salmon's analysis the meaning of $(1)^{\prime}$ is depicted by

$(1)^{\prime \prime}$ Nothing is a Holmesesque-Holmes, and he is a fictional character.

As Russell (1905) might put it, in (1)" there is no constituent that corresponds to the grammatical subject of $(1)^{\prime}$, which implies that, under Salmon's Russell-inspired proposal, use of 'The HolmesesqueHolmes' cannot provide the antecedent for the subsequent anaphoric use of 'he'.

Salmon may have been at least partially aware of this problem, for in an extended note he takes pains to explain that his proposal "preserves an anaphoric-like relation between pronoun and antecedent" (1998, p. 317, note 48). Salmon claims that his analysis preserves such a relation because 'he' in the follow-up clause of $(1)^{\prime \prime}$ has (or can have) the previous referential use of 'Holmes' occurring within the disguised definite description 'the Holmesesque-Holmes' as its antecedent. Salmon is thus suggesting that the anaphoric relation manifested by an utterance of (1) is analogous to the anaphoric relation manifested by an utterance of,

(5) The Maserati owned by Nathan doesn't exist; he is disappointed.

The speaker of (5), we may assume, does not purport to use the definite description 'The Maserati owned by Nathan' to refer, though he does, we may suppose, use the constituent term 'Nathan' to refer, and it is the referential use of this constituent term that provides the antecedent for the subsequent anaphoric pronoun. Under this interpretation of the anaphoric relation - which is the only coherent anaphoric interpretation available - the speaker is not purporting to assert of a non-existent Maserati that it is disappointed; rather the speaker is asserting of Nathan that he is disappointed. 
I concede that if a speaker of (1) did express something adequately depicted by (1)", then (1) would admit of an anaphoric interpretation analogous to the above described anaphoric interpretation of (5). The problem, however, is that we do not interpret a speaker of (1) as expressing what is depicted by an analogous anaphoric interpretation of $(1)^{\prime \prime}$. Under the analogous anaphoric interpretation of $(1)^{\prime \prime}$, the speaker expresses that there is nothing of a certain sort and moreover Holmes is a fictional character. But that is just not what we understand a speaker who utters (1) to be saying. Salmon himself suggests that what a speaker of (1) says can be expressed by a sentence in which the anaphora is supplanted by subject-ellipsis: "[(1)] may even be paraphrased into "Sherlock Holmes does not really exist and is only a fictional character" " (1998, p. 317, note 48). But (1)" does not admit of such an elliptical paraphrase. That is, what is expressed by $(1)^{\prime \prime}$ cannot be "paraphrased into",

$(1)^{\prime \prime \prime}$ Nothing is a Holmesesque-Holmes, and is a fictional character. \#

(Note that $(1)^{\prime \prime \prime}$ must be interpreted in such a way that the scope of 'Nothing' does not extend beyond the first clause.)

My second objection against Salmon's Russell-inspired proposal is that it fails to solve the referential sub-problem, even within the domain of metafictional discourse, because it illegitimately attempts to transform instances of the referential sub-problem into instances of the non-referential sub-problem. That such a transformation is illegitimate is revealed by the failure of Salmon's proposal to capture the anaphoric relations that are (as Salmon seems to agree) indicative of the referential sub-problem. Since Salmon's proposed solution cannot preserve the anaphoric relation whose presence is indicative of the problem it is designed to solve, Salmon's Russell-inspired proposal fails to provide an adequate solution.

\section{Pragmatic Meinongism, 'Really', and Pragmatic Modulation}

The upshot of the previous section is that there is no hope for a Russell-inspired solution to the referential sub-problem. It is essential to the problem that speakers of, e.g., (1) are at least purporting to use 'Sherlock Holmes' to refer to something, so any attempt to solve, or obviate, the problem by "analyzing away" the purported referring is bound to miss the mark. An adequate solution must countenance that the speaker is at least purporting to refer to something and to assert of it that it does not exist; the challenge is to explain why 
we nonetheless interpret the speaker as saying something coherent, and even intuitively true. Framed in this way a Meinong-inspired explanation seems all but forced upon us: we are compelled to accept that, at least as it is used in instances of the referential sub-problem, the negated predicate 'does not exist' is interpreted in such a way that it can be satisfied by something, by some referent. ${ }^{15}$ For if 'does not exist' as it occurs in an utterance of, e.g., (1) is expressing this more inclusive sense, we can understood the speaker as saying (or purporting to say) something that is at least coherent, if not intuitively true. ${ }^{16}$

A solution that borrows just this much from Meinong allows for an explanation of why we understand the speaker of (1) as saying something coherent, and perhaps even intuitively true, yet is immune to the objections raised in the previous section, since it countenances the datum that a speaker who utters (1) is (at least) purporting to use 'Sherlock Holmes' to refer to something. Moreover, in allowing that sometimes 'does not exist' is interpreted in this Meinong-inspired way, we are not precluded from agreeing with the citation from Quine that appears at beginning of this paper; i.e. we are not precluded from saying that other times, perhaps even typically, 'does not exist' is interpreted in such a way that nothing could fail to exist. If we reject the assumption that uses of 'exists' and 'does not exist' receive the same univocal interpretation in every discourse context, we can maintain that, as it is used in occurrences of negative existentials that give rise to the nonreferential sub-problem, 'does not exist' is interpreted as expressing Quine's preferred exclusive sense, yet also maintain that, as it is used in occurrences of negative existentials that give rise to the referential sub-problem, 'does not exist' is interpreted as expressing a Meinong-inspired inclusive sense. We can therefore agree with Quine when he sincerely asserts 'Everything exists' and yet also agree with (or at least charitably interpret) a speaker who sincerely utters (1).

Given that the referential sub-problem cannot be solved by a Russell-inspired approach, I think we have no choice but to pursue the Meinong-inspired strategy I have outlined. One might worry,

${ }^{15}$ We need not, and cannot, say, "it is possible that something that exists does not exist." Care must be taken to distinguish the verb 'to exist' from existential quantification. This significant, yet often over-looked, distinction is stressed by Parsons (1980), Miller (1986), and Moltmann (2020).

${ }^{16}$ Salmon (1998), (2014), provides several interesting examples that, according to him, involve successful reference to past and merely possible entities that satisfy 'does not now actually exist'. 
however, that the requisite contextual variation of 'does not exist' is an ad hoc device, motivated only by the problem it is invoked to solve. This worry is reinforced by the observation that the verb "to exist' is not an indexical; i.e. setting aside tense-inflections, 'to exist' is not as a matter of its conventional linguistic meaning a contextsensitive word. In Kaplan's (1989) familiar terminology, the character of 'to exist' cannot plausibly be taken to be a non-constant function from contexts to contents. So, if 'does not exist' is often, perhaps typically, interpreted as expressing Quine's exclusive sense, yet uses of 'does not exist' that give rise to the referential sub-problem are interpreted as expressing a distinct inclusive sense, then this contextual variation of interpretation can only be the result of a process of pragmatic modulation. But is there any independent reason for thinking that such pragmatic modulation occurs? The remainder of this section will be concerned to address this worry. I will argue that, given the ubiquity of the phenomenon known as pragmatic modulation, appeal to such contextual variation is by no means ad hoc; to the contrary, what would be ad hoc is insistence that the verb 'to exist' differs from nearly every other verb in not being subject to such pragmatic modulation. Before proceeding, however, it should be noted that my point here is empirical and descriptive. Perhaps metaphysicians engaged in ontological debates should use "does not exist' in the exclusive sense favored by Quine and other ontologists. Perhaps using this negated predicate to express an inclusive sense - a sense that allows for the possibility that something fails to existwill lead to confusion, maybe even absurdities. ${ }^{17} \mathrm{I}$ do not take issue with such prescriptive claims; I am concerned to argue only that competent speakers and interpreters $d o$ sometimes use 'does not exist' in the inclusive way that is required by the Meinong-inspired solution to the referential sub-problem.

Let us begin by distinguishing between two versions of (1), a modified version that contains the adverb 'really' (and the modifier 'just' in the follow-up clause), and an unmodified version that does not contain 'really' (nor 'just'):

$\left(1^{m}\right)$ Sherlock Holmes doesn't really exist; he's just a fictional character.

${ }^{17}$ Van Inwagen (2003) argues that using 'does not exist' to express the more inclusive sense will lead either to the absurd result that some things are not selfidentical, or to an unfortunate ambiguity of existential quantifiers. The reductio, however, conflates questions about the domain of existential quantification and questions about the extension of the predicate 'exists'. 
$\left(1^{u}\right)$ Sherlock Holmes doesn't exist; he's a fictional character.

Solving the referential sub-problem requires explaining how we understand a speaker who utters either $\left(1^{m}\right)$ or $\left(1^{u}\right)$ as saying something coherent, and even intuitively true, but such minimal pairs manifest several related phenomena that also cry for explanation. Evans observes that uses of $\left(1^{m}\right)$ and $\left(1^{u}\right)$ are "very closely related", and he states that "although ['really'] is explicitly used only on some of the occasions on which singular negative existential statements are made, I take it to be understood on the occasions on which it is not explicitly used" (1982, pp. 369-370). I agree with Evans on this point, or, to be a bit more precise, I agree that utterances of unmodified negative existentials that give rise to the referential subproblem are understood as equivalent to their modified cousins. We should distinguish, however, Evans' (correct) observation that what a speaker who utters $\left(1^{u}\right)$ is understood as saying is equivalent to what a speaker who utters $\left(1^{m}\right)$ is understood as saying from the (incorrect) claim that sentences $\left(1^{m}\right)$ and $\left(1^{u}\right)$ have the same literal conventional meaning. For, as the citation from Evans suggests, there is a clear sense that what a speaker says by uttering $\left(1^{u}\right)$ would be more $e x$ plicitly said by uttering $\left(1^{m}\right)$.

Now consider these minimal pairs of uncontentious sentences - uncontentious in that they do not contain the predicate "does not exist':

$\left(5^{m}\right)$ Nancy isn't really American; she's just Californian.

$\left(5^{u}\right)$ Nancy isn't American; she's Californian. ${ }^{18}$

$\left(6^{m}\right)$ Bernie isn't really rich; he's just financially very comfortable.

$\left(6^{u}\right)$ Bernie isn't rich; he's financially very comfortable.

$\left(7^{m}\right)$ Laura doesn't really run; she's just a jogger.

$\left(7^{u}\right)$ Laura doesn't run; she's a jogger.

$\left(8^{m}\right)$ Sam doesn't really weigh 80 kilos; he just weighs 80 kilos clothed. ${ }^{19}$

$\left(8^{u}\right)$ Sam doesn't weigh 80 kilos; he weighs 80 kilos clothed.

${ }^{18}$ https://fivethirtyeight.com/features/only-20-percent-of-voters-are-real-americans/

${ }^{19} \mathrm{I}$ include this example because 'weighs 80 kilos' seems to pattern like 'exists'. Moltmann (2013), (2020), observes that 'exists' does not accept location modifiers, unless applied to an abstract subject. 'Rabbits exist in Spain' sounds fine, as does 'Rabbits weigh 80 kilos in Spain'. 'Boris exists in Spain' sounds very odd, as does 'Boris weighs 80 kilos in Spain'. 
These minimal pairs manifest phenomena obviously analogous to the above described phenomena manifested by $\left\langle\left(1^{m}\right),\left(1^{u}\right)\right\rangle$. A speaker of $\left(7^{u}\right)$ will be interpreted, as Evans might put it, as though there were an implicit occurrence of 'really' in her utterance. Nonetheless, the literal meaning of the sentence $\left(7^{m}\right)$ clearly differs from the literal meaning of the sentence $\left(7^{u}\right)$; what a speaker says in uttering $\left(7^{u}\right)$ would be more explicitly said by uttering $\left(7^{m}\right)$. That there is a difference in literal meaning between an unmodified sentence and its modified cousin is further evidenced by the observation that an utterance of $\left(7^{u}\right)$ is susceptible to pedantic objections to which an utterance of $\left(7^{m}\right)$ is immune. A pedant might object that since jogging is, arguably anyway, a way of running, a speaker of $\left(7^{u}\right)$ says something incoherent: if jogging is a way of running, how could there be a jogger who does not run? A speaker of $\left(7^{m}\right)$, in contrast, is immune to this objection; even if jogging is a way of running, it may not be a way of really running, so there could be a jogger who does not really run. (I have focused here on $\left\langle\left(7^{m}\right),\left(7^{u}\right)\right\rangle$, as this example resembles $\left\langle\left(1^{m}\right),\left(1^{u}\right)\right\rangle$ in that 'really' is used to modify a verb, but my remarks apply mutatis mutandis to the other examples.)

Given that the contentious pair $\left\langle\left(1^{m}\right),\left(1^{u}\right)\right\rangle$ and the uncontentious pairs $\left\langle\left(5^{m}\right),\left(5^{u}\right)\right\rangle-\left\langle\left(8^{m}\right),\left(8^{u}\right)\right\rangle$ manifest the same, or at least obviously similar, phenomena, a proposed explanation of the phenomena manifested by $\left\langle\left(1^{m}\right),\left(1^{u}\right)\right\rangle$ can be deemed adequate only if it applies, mutatis mutandis, to the analogous phenomena manifested by $\left\langle\left(5^{m}\right),\left(5^{u}\right)\right\rangle-\left\langle\left(8^{m}\right),\left(8^{u}\right)\right\rangle$. In other words, one might legitimately object against a proposed explanation that applied to $\left\langle\left(1^{m}\right),\left(1^{u}\right)\right\rangle$ but not to $\left\langle\left(5^{m}\right),\left(5^{u}\right)\right\rangle-\left\langle\left(8^{m}\right),\left(8^{u}\right)\right\rangle$ that it is ad hoc and lacks independent motivation. ${ }^{20}$ Conversely, one could not object on these grounds against an explanation that applied not only to $\left\langle\left(1^{m}\right),\left(1^{u}\right)\right\rangle$ but also to $\left\langle\left(5^{m}\right),\left(5^{u}\right)\right\rangle-\left\langle\left(8^{m}\right),\left(8^{u}\right)\right\rangle$. In what follows I will first propose a semantic analysis of 'really' that applies not only to $\left(1^{m}\right)$ but also to $\left(5^{m}\right)-\left(8^{m}\right)$. I will then demonstrate that the combination of this semantic analysis and the claim that $\left(1^{u}\right)$ as well as $\left(5^{u}\right)-\left(8^{u}\right)$ involve pragmatic modulation of a negated predicate provides a compelling explanation of the phenomena manifested by all the relevant minimal pairs. Uncontentious minimal pairs $\left\langle\left(5^{m}\right),\left(5^{u}\right)\right\rangle-\left\langle\left(8^{m}\right),\left(8^{u}\right)\right\rangle$ thus

${ }^{20}$ Evans' (1982) proposal falls to this ad hoc objection. Evans notes that under his proposal we cannot understand, e.g., $\left(1^{m}\right)$ "without knowing what game of makebelieve or pretense one would have to play in order to quasi-understand" (1982, pp. 371-372). But this restriction blocks Evans' proposal from applying to utterances of sentences $\left(5^{m}\right)-\left(8^{m}\right)$, as understanding such utterances does not require knowledge of any such pretense. 
provide pragmatic Meinongism with independent evidence of the requisite pragmatic modulation of 'does not exist'.

What is the semantic significance of the modifier 'really' in $\left(5^{m}\right)$ $\left(8^{m}\right)$ ? Schaffer observes that " "real' is used flexibly in ordinary English to reflect a multitude of distinctions" (2009, p. 360), but he suggests that one prominent such distinction is "that between paradigm and deviant cases" (2009, p. 360 , note 15$)$. I propose that it is this distinction that is reflected by the use of 'really' in $\left(5^{m}\right)-\left(8^{m}\right)$, and thus, I infer, also reflected in negative existentials such as $\left(1^{m}\right)$. In the most relevant case where 'really' is used to modify a verb-phrase, a rough characterization of the semantic significance of 'really' is provided by the following schema:

$x$ satisfies $\ulcorner$ really $V s\urcorner$ iff $x$ is a paradigmatic instance of something that $V \mathrm{~s}$

This characterization of the semantic significance of the modifier 'really' in $\left(1^{m}\right)$ and $\left(5^{m}\right)-\left(8^{m}\right)$ provides a straightforward account of how each modified sentence differs from its unmodified cousin, and thereby explains why a speaker who utters, e.g., $\left(7^{m}\right)$ is immune to the pedantic objection to which a speaker of $\left(7^{u}\right)$ is susceptible. A speaker who utters $\left(7^{m}\right)$ makes it explicit that she is committed only to the claim that a jogger is not a paradigmatic instance of something that runs. In contrast, a speaker who utters $\left(7^{u}\right)$ does not explicitly block an uncharitable interpretation according to which she is committed to the, arguably incoherent, claim that some jogger does not run.

The above schema characterizes how relevant uses of 'really' modify the meaning of a verb it is combined with, but such modification may not thereby clarify the satisfaction conditions of the (modified) verb's occurrence. We may have no better idea of what it takes for something to satisfy 'really runs' than we do of what it takes for something to satisfy 'runs'. Indeed, for some verbs we may have a better idea of what it takes for something to satisfy the unmodified verb-phrase, since we may have a relatively stable, contextually invariant, idea of what is required for something to satisfy $\left\ulcorner V_{\mathrm{s}}\right\urcorner$, and not have a stable, contextually invariant, idea of what is required for something to paradigmatically satisfy $\ulcorner V s\urcorner$. Indeed, 'exists' seems to be such a verb, as it is not clear, and may even be underdetermined, what it is for something to paradigmatically exist. This observation sheds light on the illocutionary point of the follow-up clauses of $\left(1^{m}\right)$ and $\left(5^{m}\right)-\left(8^{m}\right)$ : since it often is not clear, and perhaps is even 
underdetermined, what is required for something to paradigmatically satisfy $\ulcorner V s\urcorner$, speakers of such sentences are compelled to provide their interlocutors with at least some guidance concerning how they are to be interpreted. A speaker of, e.g., $\left(7^{m}\right)$ utters the follow-up clause to clarify that someone who is just a jogger is not a paradigmatic instance of something that runs, and thus does satisfy 'doesn't really run'. And similarly, a speaker of $\left(1^{m}\right)$ utters the follow-up clause to clarify that something that is just a fictional character is not a paradigmatic instance of something that exists, and thus does satisfy 'doesn't really exist'. ${ }^{21}$ (Or, if there existed such things as fictional characters, they would nonetheless not paradigmatically exist, and thus would satisfy 'does not really exist' as it is used by the speaker.)

This account of the semantic significance of 'really' in effect provides us with a semantic Meinong-inspired solution to the referential sub-problem as it arises for modified negative existentials such as $\left(1^{m}\right)$. For this account of the semantic significance of 'really' implies that 'doesn't really exist' as it occurs in $\left(1^{m}\right)$ expresses the Meinonginspired inclusive sense according to which some things can satisfy it - viz. things that exist, yet do not paradigmatically exist. And the illocutionary point of the follow-up of $\left(1^{m}\right)$ is thus, at least in part, to clarify that, at least according to the speaker, fictional characters are not paradigmatic instances of things that exist, and so, as she is using 'doesn't really exist', this predicate is satisfied by things that are just fictional objects. Since it is plausible that fictional characters are not paradigmatic instances of things that exist, there is no mystery as to why we interpret a speaker of $\left(1^{m}\right)$ as saying something not only coherent, but even intuitively true: if we are willing to accommodate the presupposition that there are fictional characters, and we grant that such things would not paradigmatically exist, we will understand a speaker who utters $\left(1^{m}\right)$ as saying something true.

What about unmodified negative existentials such as $\left(1^{u}\right)$ ? Why do we also interpret a speaker who sincerely utters an unmodified nega-

${ }^{21}$ An anonymous referee suggested that 'does not really exist' should be interpreted as meaning is not concrete. Though this may be correct for some uses of 'does not really exist', I think it would be a mistake to suppose all uses, or even typical uses, are to be interpreted in this way. First, note that uses of negative existentials that explicitly deny the real existence of concrete entities are not incoherent; we can charitably interpret a speaker who utters, 'That concrete object does not really exist; it is merely an object of perception'. Second, though a speaker who asserts 'Sherlock Holmes does not exist; he's merely a fictional character' seems to be thereby committed to the nonexistence of all fictional characters, it does not seem that she is thereby committed to the nonexistence of all nonconcrete entities. 
tive existential as saying something coherent, and perhaps even true? Given the structural analogies between the minimal pair $\left\langle\left(1^{m}\right),\left(1^{u}\right)\right\rangle$ and uncontentious minimal pairs $\left\langle\left(5^{m}\right),\left(5^{u}\right)\right\rangle-\left\langle\left(8^{m}\right),\left(8^{u}\right)\right\rangle$, whatever explanation we apply to account for the phenomena manifested by, e.g., $\left\langle\left(7^{m}\right),\left(7^{u}\right)\right\rangle$, the same explanation should be applied to account for the analogous phenomena manifested by $\left\langle\left(1^{m},\left(1^{u}\right)\right\rangle\right.$. Among the phenomena to be explained is that a speaker who utters $\left(7^{u}\right)$ will be charitably understood as saying what would be more explicitly said by uttering $\left(7^{m}\right)$. But this equivalence requires that the unmodified predicate 'doesn't run' as used in an occurrence of $\left(7^{u}\right)$ is understood as expressing what would be more explicitly expressed by the modified predicate 'doesn't really run'. ${ }^{22}$ Granted that 'to run' is not (in the relevant way) an indexical, the only option for explaining why 'doesn't run' is understood as expressing what would be more explicitly expressed by 'doesn't really run' is to claim that the conventional meaning of 'does not run' is pragmatically modulated so that this use of the predicate expresses a more inclusive sense. Granted that 'to exist' is also not (in the relevant way) an indexical, an analogous explanation must hold for $\left\langle\left(1^{m}\right),\left(1^{u}\right)\right\rangle$ : 'doesn't exist' as used in an occurrence of $\left(1^{u}\right)$ is understood as expressing what would be more explicitly expressed by 'doesn't really exist' because the conventional meaning of 'doesn't exist' is pragmatically modulated so that this use of the predicate expresses a more inclusive sense. ${ }^{23}$ This modulation can be viewed as involving two steps: first, the verb-phrase "does exist' is pragmatically narrowed so that the satisfaction conditions of this occurrence exclude things that do not paradigmatically exist; second, the narrowed occurrence of 'exists' is negated, resulting in

\footnotetext{
${ }^{22} \mathrm{My}$ defense of pragmatic Meinongism is neutral between two general ways of conceiving of pragmatic modulation. On the moderate conception, a predicate $\ulcorner V s$ semantically determines (perhaps relative to an index) satisfaction conditions, yet an optional process of pragmatic modulation may result in some occurrences of $\ulcorner V s\urcorner$ being interpreted as having distinct satisfaction conditions. On the radical conception, $\ulcorner V s\urcorner$ does not semantically determine satisfaction conditions (not even relative to an index), and every occurrence of $\ulcorner V s\urcorner$ requires pragmatic modulation to determine - to some degree - satisfaction conditions. For versions of the moderate conception, see Carston 2002 and Recanati 2010. For versions of the radical conception, see Carston 2019 and Pietroski 2005.

${ }^{23}$ As is evidenced by the ease with which examples such as $\left(5^{u}\right)-\left(8^{u}\right)$ can be generated, such narrowing of satisfaction conditions to meet the particular exigencies of a discourse situation is a ubiquitous phenomenon in natural language. Noveck and Spotorno (2013) present a preliminary classification of varieties of pragmatic narrowing.
} 
a more inclusive interpretation of the negated predicate "does not exist'. ${ }^{24}$

Finally, it should be noted that the follow-up clauses of unmodified sentences such as $\left(1^{u}\right)$ and $\left(5^{u}\right)-\left(8^{u}\right)$ play a dual role in guiding interpretation. As was noted above, the illocutionary point of the follow-clause of modified sentences $\left(1^{m}\right)$ and $\left(5^{m}\right)-\left(8^{m}\right)$ is to clarify - at least to some extent - how the speaker is using 'really' to alter the satisfaction conditions of the verb-phrase. The follow-up clauses in the unmodified sentences $\left(1^{u}\right)$ and $\left(5^{u}\right)-\left(8^{u}\right)$ play a similar clarificatory role, but these follow-up clauses also play a role in prompting the pragmatic modulation of the negated verb-phrase. As was noted above, the presence of the anaphoric relation in the follow-up clause of $\left(1^{u}\right)$ coerces us to interpret an utterance of $\left(1^{u}\right)$ as giving rise to the referential sub-problem. Since the modifier 'really' is not present in these cases, nothing in the literal conventional meaning of $\left(1^{u}\right)$ blocks a pedantic interpretation according to which the speaker is committed to the incoherent claim that something satisfies 'does not exist', where the predicate is taken to express the exclusive sense. Confronted with this threatened incoherence, a charitable, nonpedantic, interpreter seeks an alternative interpretation that avoids this incoherence. The follow-up clause of $\left(1^{u}\right)$ thus serves, first, to prompt a charitable, non-pedantic, interpreter to pragmatically modulate 'doesn't exist' so that it expresses an inclusive sense according to which it can be satisfied by something, and it also serves, second, to clarify this pragmatically modulated use of the predicate at least this much: as the speaker is using 'does not exist', this predicate is satisfied by fictional characters. The follow-up clauses of, e.g., $\left(5^{u}\right)-$ $\left(8^{u}\right)$ play analogous dual roles.

Let us take stock. The pragmatic Meinongian solution to the referential sub-problem requires that though 'does not exist' is often, perhaps even typically, interpreted as expressing an exclusive sense, as it used in negative existentials such as $\left(1^{u}\right)$ it is interpreted as expressing an inclusive sense. I suggested above that one might worry that this solution is ad hoc, i.e. that there is no reason independent of the referential sub-problem for thinking that uses of 'does not exist' are pragmatically modulated in the requisite way. In response to this worry, I observed that minimal pairs of negative existentials that give rise to the referential sub-problem, e.g. $\left\langle\left(1^{m}\right),\left(1^{u}\right)\right\rangle$, and myriad minimal pairs of structurally analogous uncontentious sen-

\footnotetext{
${ }^{24}$ I am not suggesting that these steps correspond chronologically to actual cognitive processing.
} 
tences, e.g. $\left\langle\left(5^{m}\right),\left(5^{u}\right)\right\rangle-\left\langle\left(8^{m}\right),\left(8^{u}\right)\right\rangle$, manifest the same, or at least obviously analogous, phenomena. I then argued that the best explanation of all instances of these phenomena, i.e. not only as manifested by $\left\langle\left(1^{m}\right),\left(1^{u}\right)\right\rangle$ but also as manifested by $\left\langle\left(5^{m}\right),\left(5^{u}\right)\right\rangle-\left\langle\left(8^{m}\right),\left(8^{u}\right)\right\rangle$, requires holding that a process of pragmatic modulation allows a speaker who utters the unmodified sentence to say what would be more explicitly said by uttering its modified cousin. So, minimal pairs of uncontentious sentences such as $\left\langle\left(5^{m}\right),\left(5^{u}\right)\right\rangle-\left\langle\left(8^{m}\right),\left(8^{u}\right)\right\rangle$ - and it would be a trivial exercise to generate more - provide an independent reason for positing the requisite pragmatic modulation of 'does not exist'.

\section{Pragmatic Meinongism and Feelings for Reality}

I maintain that to solve the referential problem we must follow Meinong in allowing that sometimes 'does not exist' is used in such a way that something can satisfy it. But we need not follow Meinong into the jungle. That is, pragmatic Meinongism ought not be taken to imply ontological commitment to fictional characters, numbers, possible men in the doorway, or any other purported referent of an intuitively true negative existential. Why might one take pragmatic Meinongism to imply, or at least provide support for, e.g., fictional realism? One might reason as follows:

First, consider a fictional realist who endorses pragmatic Meinongism. Because she endorses pragmatic Meinongism, she accepts that a speaker who utters (1) at least purports to refer to something with 'Sherlock Holmes', and since she also endorses fictional realism, she will maintain that the speaker moreover successfully refers to something. And this provides her with a straightforward explanation of why we interpret a speaker of (1) as saying something intuitively true: what the speaker says is intuitively true because it is true. Given the pragmatic modulation of 'does not exist', the referent of her use of 'Sherlock Holmes' satisfies her use of 'does not exist'.

Second, consider a fictional nihilist who endorses pragmatic Meinongism. Because he endorses pragmatic Meinongism, he also accepts that a speaker who utters (1) at least purports to refer to something with 'Sherlock Holmes', but since he endorses fictional nihilism, he must maintain that the speaker fails to refer to something. And this precludes him from giving a straightforward explanation of why we interpret the speaker as saying something intuitively true: even granted the pragmatic modulation of the predicate 'does not exist', a fictional nihilist cannot claim that the speaker successfully refers to something that satisfies the (pragmatically modulated) predicate. 
So, pragmatic Meinongism provides fictional realism with an explanation of why a speaker who utters (1) says something intuitively true, but it does not provide fictional nihilism with such an explanation. The reason then that pragmatic Meinongism implies fictional realism over fictional nihilism is that pragmatic Meinongism combined with fictional realism solves the referential sub-problem, whereas pragmatic Meinongism combined with fictional nihilism does not. ${ }^{25}$

This line of reasoning threatens to lead us not only into Meinong's jungle, but also into the murky waters of the metametaphysical problem of ontological commitment, the problem of determining the conditions under which thinkers and speakers are committed to there being entities corresponding to their thought and speech. I believe, however, that I can bring out the flaw in the above line of reasoning without wading too far into these murky waters. Suppose you are a fictional nihilist; you deny that there are such things as fictional characters, and so according to your views of ontological commitment, whatever they are, our metafictional thought and speech does not commit us to there being such things. Now, quite independently of the referential sub-problem, as a fictional nihilist you have some explaining to do: you must provide alternative, not-straightforward, explanations of all the data concerning our metafictional thought and speech that motivate van Inwagen et al. to endorse fictional realism. Consider one such datum: we interpret a speaker who utters (2) as saying something intuitively true. The fictional realist is motivated to provide a straightforward explanation of this datum: according to fictional realists, a speaker of (2) says something literally true. How is the fictional nihilist going to explain this datum? That is a good question, but, thankfully, indicating the flaw in the above line of reasoning does not require me to answer it. ${ }^{26} \mathrm{I}$ need only point out

${ }^{25}$ An analogous line of reasoning would seem to show that pragmatic Meinongism supports fictional realism over fictional anti-realism - the view that there is no fact of the matter as to whether there are fictional characters. And a response analogous the one provided below would make clear the flaw in analogous line of reasoning. See Yablo 2001 and Chalmers 2009 for alternative, Carnap-inspired, ways of developing general forms of ontological anti-realism.

${ }^{26}$ Fictional nihilists have provided some insightful answers. Walton's (1990) influential idea is, roughly, that utterances performed within a certain linguistic pretense can make truth-evaluable claims about the facts outside the pretense even if the speaker merely purports to refer. And Reimer (2001, p. 24l) proposes that "the intuition that something truth-evaluable is said in such cases is to be accounted for by the hypothesis that we, as speakers of the language, presuppose a Meinongian ontology [and thus] that there is no reason, based on the intuitive data alone, to suppose that there are indeed Meinongian objects and individuals" (my emphasis). 
that fictional nihilism faces this explanatory challenge independently of the solution to the referential sub-problem provided by pragmatic Meinongism. Every intuitively true utterance in which the speaker purports to refer to something using a fictional name poses this explanatory challenge for fictional nihilism. If pragmatic Meinongism is correct, utterances of negative existentials such as (1) are just one variety of such utterances. So, though fictional nihilism combined with pragmatic Meinongism faces an explanatory challenge regarding negative existentials such as (1) that fictional realism combined with pragmatic Meinongism does not face, it does not follow that pragmatic Meinongism supports fictional realism over fictional nihilism, for the "additional" explanatory challenge arises independently of the solution to the referential sub-problem provided by pragmatic Meinongism.

In making this final point in defense of pragmatic Meinongism, I have focused on fictional realism, fictional nihilism, and negative existentials such as (1). But the point clearly generalizes: for analogous reasons pragmatic Meinongism applied to negative existentials such as (3) does not favor possibilia realism over possibilia nihilism; pragmatic Meinongism applied to negative existentials such as (4) does not favor numerical realism over numerical nihilism; etc. In general, the solution to the referential sub-problem provided by pragmatic Meinongism is independent of these ontological debates. Moreover, one might take this independence as itself a point in favor of pragmatic Meinongism. In motivating his broadly anti-realist view of ontological commitment, Yablo reflects,

It takes a good deal of training before one can bring oneself to believe in an undiscovered fact of the matter as to the existence of nineteen, never mind Chicago and Spanish. And even after the training, one feels just a teensy bit ridiculous pondering the ontological status of these things. (Yablo and Gollois 1998, p. 230)

Those of us who share Yablo's sentiment can view it as a virtue of pragmatic Meinongism that the solution it provides to the referential sub-problem does not imply any position on such issues of ontological status. $^{27}$

${ }^{27}$ This paper has benefited from the helpful comments of two anonymous referees. The basic idea of pragmatic Meinongism originated years ago in conversations at the IIF with Philipp Blum, Eduardo Garcia and Maite Ezcurdia, and I am grateful for their wit and insight. Though I doubt she would agree with it, I dedicate the paper to Maite. 


\section{REFERENCES}

Almog, J., J. Perry, and H. Wettstein (eds.), 1989, Themes from Kaplan, Oxford University Press, Oxford.

Carston, R., 2019, "Ad Hoc Concepts, Polysemy and the Lexicon", in K. Scott, B. Clark, and R. Carston (eds.), Relevance, Pragmatics and Interpretation, Cambridge University Press, Cambridge, pp. 150-162.

- 2002, Thoughts and Utterances: the Pragmatics of Explicit Communication, Blackwell, Oxford.

Clapp, L., forthcoming, "Negative Existentials as Corrections: A Partial Solution to the Problem of Negative Existentials in Segmented Discourse Representation Theory", Linguistics and Philosophy.

Chalmers, D., 2009, “Ontological Anti-Realism”, in D. Chalmers, D. Manley and R. Wasserman 2009, pp. 77-129.

Chalmers, D., D. Manley and R. Wasserman (eds.), 2009, Metametaphysics: New Essays on the Foundations of Ontology, Oxford University Press, Oxford.

Evans, G., 1982, The Varieties of Reference, Clarendon Press, Oxford.

Everett, A., 2007, "Pretense, Existence, and Fictional Objects", Philosophy and Phenomenological Research, vol. 74, no. 1, pp. 56-80.

Garcia-Carpintero, M. and G. Marti (eds.), 2014, Empty Representations: Reference and Non-existence, Oxford University Press, Oxford.

Geach, P., 1967, "Intentional Identity", Journal of Philosophy, vol. 64, no. 20, pp. 627-632.

Kaplan, D., 1989, "Demonstratives: An Essay on the Semantics, Logic, Metaphysics, and Epistemology of Demonstratives and Other Indexicals", in J. Almog, J. Perry, and H. Wettstein (eds.) 1989, pp. 481-566.

Kripke, S., 2013, Reference and Existence, Oxford University Press, Oxford.

Meinong, A., 1960, "The Theory of Objects", in R. Chisholm (ed.), I. Levi, B.D. Terrell, and R. Chisholm (trans.), Realism and the Background of Phenomenology, Ridgeview Publishing, New York, pp. 76-117.

Miller, B., 1986, "Exists' and Existence", The Review of Metaphysics, vol. 40, no. 2, pp. 237-270.

Moltmann, F., 2020, "Existence Predicates", Synthese, vol. 197, pp. 311335.

- _ 2013, "The Semantics of Existence", Linguistics and Philosophy, vol. 36, pp. 31-63.

Noveck, I. and N. Spotorno, 2013, "Narrowing", in L. Goldstein (ed.), Brevity, Oxford University Press, Oxford.

Parsons, T., 1980, Nonexistent Objects, Yale University Press, New Haven.

Pietroski, P., 2005, "Meaning Before Truth", in G. Preyer and G. Peter (eds.), Contextualism in Philosophy: Knowledge, Meaning, and Truth, Oxford University Press, Oxford. 
Priest, G., 2005, Towards Non-Being: The Logic and Metaphysics of Intentionality, Clarendon, Oxford.

Quine, W.V.O., 1948, “On What There Is", Review of Metaphysics, vol. 2, pp. 21-38.

Recanati, F., 2010, Truth Conditional Pragmatics, Oxford University Press, Oxford.

Reimer, M., 2001, “A 'Meinongian' Solution to a Millian Problem”, American Philosophical Quarterly, vol. 38, no. 3, pp. 233-248.

Russell, B., 1919, Introduction to Mathematical Philosophy, George Allen and Unwin, London.

—_, 1905, “On Denoting”, Mind, vol. 14, no. 56, pp. 479-493.

Sainsbury, M., 2009, Fiction and Fictionalism, Routledge, London.

Salmon, N., 2014, "What is Existence?", in M. Garcia-Carpintero and G. Marti (eds.) 2014, pp. 245-261.

—_, 1998, "Nonexistence", Noûs, vol. 32, no. 3, pp. 277-319.

Schaffer, J., 2009, "On What Grounds What", in D. Chalmers, D. Manley, and R. Wasserman (eds.) 2009, pp. 347-383.

Thomasson, A., 1999, Fiction and Metaphysics, Cambridge University Press, Cambridge.

Van Inwagen, P., 2003, "Existence, Ontological Commitment, and Fictional Entities", in M. Loux, and D. Zimmerman (eds.), Oxford Handbook of Metaphysics, Oxford University Press, Oxford.

- , 1977, "Creatures of Fiction", American Philosophical Quarterly, vol. 14, no. 2, pp. 299-308.

Von Solodkoff, T., 2014, "Fictional Realism and Negative Existentials", in M. Garcia-Carpintero and G. Marti (eds.) 2014, pp. 333-352.

Walton, K., 1990, Memesis as Make Believe, Harvard University Press, Cambridge.

Yablo, S., 2001, "Go Figure: A Path Through Fictionalism", Midwest Studies in Philosophy, vol. 25, no. 1, pp. 72-102.

Yablo, S. and A. Gollois, 1998, "Does Ontology Rest on a Mistake?", Proceedings of the Aristotelian Society, Supplementary Volume, vol. 72, no. 1, pp. 229-262.

Zalta, E., 1988, Intensional Logic and the Metaphysics of Intentionality, MIT Press, Cambridge.

Received: June 30, 2019; revised: November 9, 2019; accepted: January 7, 2020. 